\title{
Field Response of Two Cetoniin Chafers (Coleoptera, Scarabaeidae) to Floral Compounds in Ternary and Binary Combinations
}

\author{
ZSÓFIA LOHONYAI ${ }^{1,2}$, J. VUTS $^{3}$, J. FAIL $^{2}$, M. TÓTH ${ }^{1}$ and Z. IMREI ${ }^{1 *}$ \\ ${ }^{1}$ Plant Protection Institute, CAR HAS, H-1525, P.O. Box 102, Budapest, Hungary \\ ${ }^{2}$ SZIU, Faculty of Horticultural Science, H-1118, Ménesi str. 44., Budapest, Hungary \\ ${ }^{3}$ Rothamsted Research, West Common, Harpenden, Hertfordshire, AL5 2JQ, UK
}

(Received: 10 July 2018; accepted: 10 September 2018)

\begin{abstract}
Several synthetic floral lures have been described for the cetoniin scarabs Cetonia aurata aurata L. and Potosia cuprea Fabr. (Coleoptera, Scarabaeidae), exploiting their olfaction-guided behavioural preference for a wide range of flower volatiles.

A ternary mixture of 3-methyl eugenol, 1-phenylethanol and $(E)$-anethol has previously been described as a powerful synthetic floral attractant for both C. a. aurata and P. cuprea. The first objective of the present research was to test whether isoeugenol and eugenol, with a very similar molecular structure to 3-methyl eugenol, can substitute 3-methyl eugenol in the ternary blend. All baited traps caught significantly more of both species than unbaited control traps, however, traps containing 3-methyl eugenol caught significantly more than those with either isoeugenol or eugenol. This indicates a fine tuning in behavioural response to 3-methyl eugenol.

The second objective was to devise simpler attractant combinations for C. a. aurata and P. cuprea, based on previous field studies with synthetic floral compounds. Both C. a. aurata and P. cuprea showed strong attraction to the combination of 2-phenylethanol and 4-methoxyphenethyl alcohol, while the combination of 2-phenylethanol and 1,2,4-trimethoxybenzene resulted in medium-size catches, however, mostly catching $P$. cuprea. This level of selectivity may lead to the development of more selective lures for $P$. cuprea, and provide a better understanding of the feeding-related olfactory ecology of the two important pest chafer species.
\end{abstract}

Keywords: Cetonia a. aurata, Potosia cuprea, Cetoniinae, floral lure, trapping.

Cetonia aurata aurata L. (Coleoptera, Scarabaeidae, Cetoniinae) occurs in Eurasia, from the Atlantic Ocean to North-Western China and Mongolia, while the closely related Potosia cuprea Fabr. (Coleoptera, Scarabaeidae, Cetoniinae) is present in the entire Palaearctic region (Hommonay and Hommonayné-Csehi, 1990). The adults of both species can damage the generative parts of several orchard and ornamental trees, including the flowers and different phenology stages of the ripening fruit (Hurpin, 1962).

Cetoniin chafers, including C. a. aurata and P. cuprea, were earlier considered to be only secondary pests (Hurpin, 1962; Hommonay and Hommonayné-Csehi, 1990), however, their importance has recently been recognized more widely. Consequently, the demand is growing for monitoring and selective control of cetoniin chafers both in Europe

* Corresponding author; e-mail: imrei.zoltan@agrar.mta.hu 
(Voigt et al., 2005; Vuts et al., 2010a) and Asia (Chen and Li, 2011). In China, for example, Protaetia (Potosia) brevitarsis Lewis feeds on sweetcorn, causing serious economic damage (Chen and Li, 2011). Advances in the evaluation of economic importance of cetoniins is partly due to the new trapping tools becoming available for several pest species (Vuts et al., 2010a; Vuts et al., 2010b).

Beyond their agricultural importance, even human medicinal aspects of the Cetoniinae have emerged recently (Lee et al., 2014). In Korea, larvae of P. brevitarsis, used as a traditional oral medicine to treat various liver diseases, are at present under investigation to identify novel bioactive substances that can be exploited as therapeutics (Lee et al., 2014).

In the present circumstances in agriculture it seems advantageous to develop trap/ bait combinations more powerful and selective based on the knowledge already available to achieve tools more efficient for monitoring or mass trapping purposes of different cetoniin species starting from the moderately selective trap/bait combinations already available (Vuts et al., 2010a). The development of new attractants and the improvement of available combinations for cetoniins in general is especially important, as their chemical control during the generative phenology stages of the crop, such as flowering, fruit setting and ripening, is restricted if possible at all (Vuts et al., 2010b).

There are substantial differences in the bouquet of flowers visited by cetoniin chafers, with significant variation even within individuals of the same plant species depending on environmental conditions and the phenotype of the plant (Knudsen et al., 2006). Cetoniin scarabs respond to a wide range of floral compounds, according to earlier findings in South Africa (Donaldson et al., 1990). Synthetic floral blends were optimised in Europe for C. a. aurata and P. cuprea (Imrei, 2003; Tóth et al., 2005; Vuts et al., 2010b), Epicometis hirta Poda (Schmera et al., 2004; Tóth et al., 2004; Vuts et al., 2010c), Oxythyrea funesta Poda (Vuts et al., 2008) and Oxythyrea cinctella Poda (Vuts et al., 2012) (Coleoptera, Scarabaeidae, Cetoniinae).

In Hungary and neighbouring countries, $C$. a. aurata and $P$. cuprea rank among the most destructive horticultural pests in peach orchards and plantations of related fruit trees (Voigt et al., 2005). Exploring new attractant combinations and studying the replaceability of components could lead to more effective and selective lures for these two species, and may also lead to the discovery of attractants for other chafers. In addition, such studies would assist in more in-depth understanding of the host plant-related chemical ecology of cetoniin chafers, thereby contributing to the prevention of unwanted catches of economically irrelevant, non-target, non-harmful, less abundant or even protected scarabs or other insect taxa, especially in environments where such encounters have higher probability. Also, prevention of unwanted catches helps maintain the capture capacity of traps longer.

Thus, our first objective was to test whether the isomers isoeugenol and eugenol can substitute 3-methyl eugenol in its known blend with 1-phenylethanol and $(E)$-anethol (Tóth et al., 2005) or change the range of cetoniin species attracted. This ternary mixture, the components of which are ubiquitous floral volatiles (Knudsen et al., 2006), proved to be attractive for adults of both $C$. a. aurata and $P$. cuprea (Tóth et al., 2005). Although the addition of $( \pm$ )-lavandulol increases $C$. a. aurata and $P$. cuprea catches (Vuts et al., 2010 b), we chose the simpler ternary combination to measure the effect of replacing one component, as we expected more apparent differences when a smaller number of components are involved. 
Our second objective was to develop simpler binary attractant combinations for cetoniin chafers by field-testing a number of floral compounds. Since there had been some evidence for the attraction of C. a. aurata and P. cuprea to 2-phenylethanol (Imrei, 2003), this compound was used as a basis to which to add other floral compounds singly.

\section{Materials and Methods}

\section{Bait dispensers}

Polyethylene sachet dispensers (Imrei and Tóth, 2002) were prepared by putting a $1 \mathrm{~cm}$ piece of dental roll into a tight polyethylene bag $(1.5 \times 1.5 \mathrm{~cm}$, wall thickness: $0.02 \mathrm{~mm}$ ). Dispensers were wrapped in aluminium foil and stored at $-30{ }^{\circ} \mathrm{C}$ until use. Chemicals used were obtained from Sigma-Aldrich Kft. (Budapest, Hungary) and were $>95 \%$ pure as stated by the supplier, which were the following: 1,2,4-trimethoxybenzene, 1-phenylethanol, 2-phenylethanol, 3-methyl eugenol, 4-methoxyphenethyl alcohol, 4-oxoisophorone, (E)-anethol, eugenol, benzaldehyde, benzyl acetate, benzyl alcohol, isoeugenol, isosafrol, methyl salicylate.

\section{Traps}

In the tests, CSALOMON ${ }^{\circledR}$ VARb3 modified funnel traps (produced by Plant Protection Institute, CAR HAS, Budapest, Hungary) were used (Imrei, 2003; Schmera et al., 2004). Photos of the traps can be viewed at www.csalomontraps.com. C. a. aurata and $P$. cuprea showed only weak colour sensitivity in previous tests (Tóth et al., 2005).

\section{Experimental sites}

Experiments were conducted at Budapest (Hungary) in a bushy area with mostly wild rose (Rosa canina L.) and hawthorn (Crataegus spp.), from the $24^{\text {th }}$ June to the $11^{\text {th }}$ July 2016. Traps within a replicate were set up ca $10 \mathrm{~m}$ apart in a randomized complete block design. Traps were inspected twice weekly, and captured scarabs were identified, recorded and removed.

Experiment 1. All three compounds, i.e., 1-phenylethanol, $(E)$-anethol and either 3-methyl-eugenol, eugenol or isoeugenol as a third component (200 $\mu 1$ each as neat), were loaded into the same single dispenser. Traps with blue upper funnels were used, as both species could be trapped in large numbers in blue traps baited with the known floral lure (Tóth et al., 2005; Vuts et al., 2010b). Four replicates of each trap/bait combination were set up, including chemically unbaited control traps, with blue coloured upper part.

Experiment 2. Test compounds were loaded (200 $\mu 1$ each as neat) in separate dispensers. Traps with fluorescent yellow upper funnels were used, as such traps baited with the known floral lure were also efficient in previous studies for the capture of both studied and other cetoniin species (Tóth et al., 2005). Three replicates of each trap/bait combinations were set up including chemically unbaited control traps, with yellow coloured upper part. 


\section{Statistics}

Statistical analyses were conducted by the software packages StatView ${ }^{\circledR}$ v4.01 and Super ANOVA ${ }^{\circledR}$ v1.11 (Abacus Concepts Inc., Berkeley, CA). As even transformed data did not meet the assumptions of a parametric test, the non-parametric Kruskal-Wallis test was used. When the Kruskal-Wallis test indicated significant differences, pairwise comparisons by Mann-Whitney U test were conducted.

\section{Results}

Experiment 1. All baited treatments caught significantly more C. a. aurata and $P$. cuprea than unbaited control traps. Catches of both species in traps baited with the ternary blend containing 3-methyl eugenol were significantly higher than those with the other ternary combinations containing eugenol or isoeugenol (Fig. 1).

Experiment 2. Significantly more C. a. aurata catches were recorded with binary combinations of 2-phenylethanol with isosafrol or 4-methoxyphenethyl alcohol than unbaited or only 2-phenylethanol-baited traps, which caught none or negligible numbers (Fig. 2). Catches with the binary combination of 2-phenylethanol and 4-methoxyphenethyl alcohol were much higher than with all other treatments, where only occasional or no catches at all were recorded.

As for $P$. cuprea, catches with 2-phenylethanol and 1,2,4-trimethoxybenzene or with 4-methoxyphenethyl alcohol were significantly higher than with all other treatments (Fig. 2).

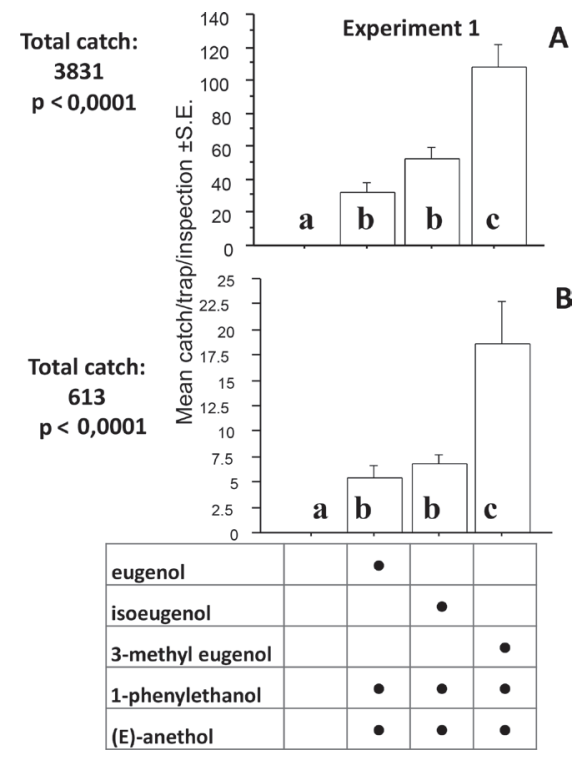

Fig. 1. Means (+ S.E.) of Cetonia a. aurata (A) and Potosia cuprea (B) specimens captured in traps baited with the combination of 1-phenylethanol and (E)-anethol, adding 3-mehyl eugenol, eugenol or isoeugenol as third component, and in unbaited traps in Experiment 1. Columns with same letter within a diagram are not significantly different at $\mathrm{P}=5 \%$ by Kruskal-Wallis, followed by Mann-Whitney U non-parametric tests 


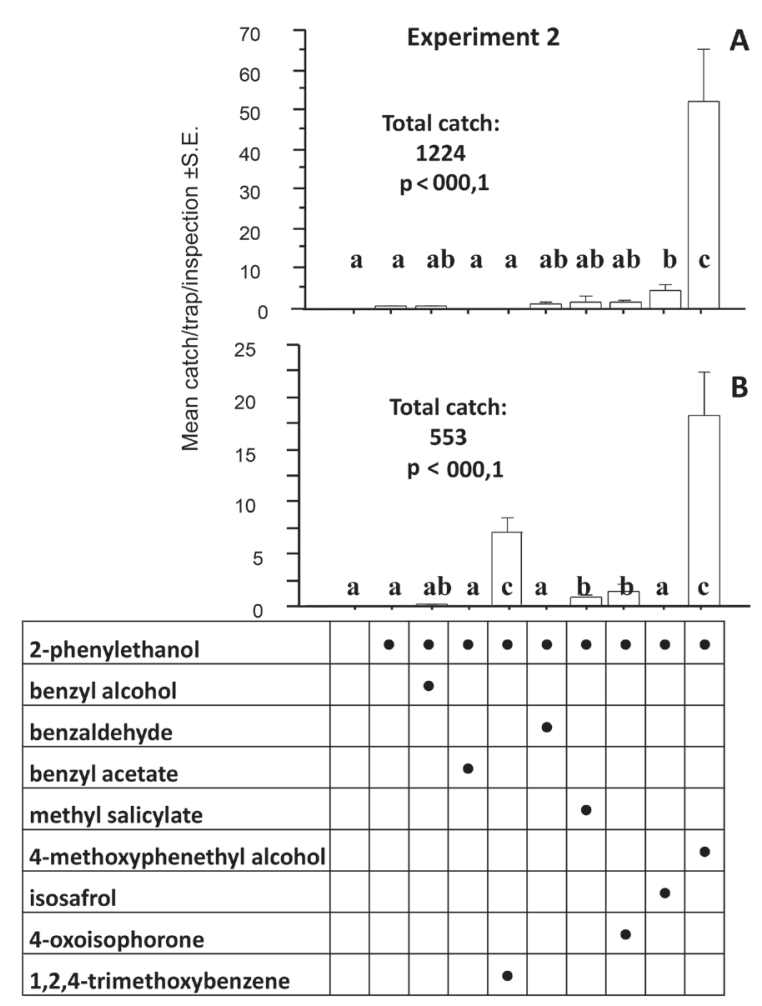

Fig. 2. Means (+ S.E.) of Cetonia a. aurata (A) and Potosia cuprea (B) specimens captured in traps baited with 2-phenylethanol, its binary combinations with ubiquitous floral compounds and in unbaited traps in Experiment 2. For significance, refer to Fig. 1

The binary combinations of 2-phenylethanol with methyl salicylate or 4-oxoisophorone caught significantly more $P$. cuprea than unbaited control and 2-phenylethanol-baited traps. There were negligible catches in the other treatments or the control.

The ratio of $P$. cuprea in traps baited with the combination of 2-phenylethanol and 1,2,4-trimethoxybenzene was significantly higher than that in 2-phenylethanol and 4-methoxyphenethyl alcohol-baited traps (Fig. 3), despite the bigger P. cuprea catches in absolute numbers in the latter treatment (Fig. 2).

\section{Discussion}

\section{Interchangeability of floral compounds with related chemical structures}

According to our present findings, despite the similarities in molecular structure, neither eugenol nor isoeugenol can replace 3-methyl eugenol in the ternary blend to reach the same level of attraction of $C$. a. aurata and P. cuprea (Fig. 1, Exp. 1). The results 


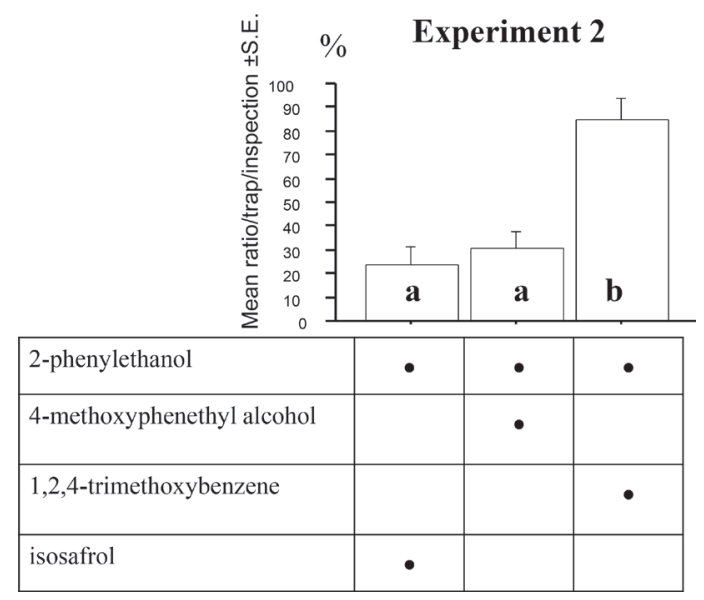

Fig. 3. Percentages of Potosia cuprea catches in total catches of Potosia cuprea and Cetonia aurata aurata together $(=100 \%)$ in traps baited with binary combinations of 2-phenylethanol with either 4-methoxyphenethyl alcohol, 1,2,4-trimethoxybenzene or isosafrol, in Experiment 2. For significance, refer to Fig. 1

demonstrate a finely tuned behavioural response of both species to 3-methyl eugenol, which might serve as a cue that indicates a certain phenological phase of the host plant (i.e. flowering or maturing fruit).

Based on the present work, it is not possible to determine the relative importance of the less active eugenol or isoeugenol in the attraction of $C$. a. aurata and P. cuprea, similarly to earlier studies by Tóth et al. (2003). Here, significantly more C. a. aurata and $P$. cuprea were attracted to eugenol in mixtures with geraniol and phenethyl propionate compared to the theoretical zero catch, whereas eugenol alone showed only a very weak attraction to $P$. cuprea. Consequently, from the practical viewpoint, 3-methyl eugenol should not be replaced by eugenol or isoeugenol.

Lampman and Metcalf (1987) found that eugenol cannot be replaced with 3-methyl eugenol to attract Diabrotica barberi Smith and Lawrence (Coleoptera: Chrysomelidae). The behavioural response of the beetle indicated that it is more tuned to eugenol, as traps baited with this compound caught 3 times more adults than 3-methyl eugenol-baited ones.

However, Lampman and Metcalf (1987) also described an example of replaceability, where a three-component mixture of veratrole, indole and phenylacetaldehyde, suitable to attract Diabrotica undecimpunctata howardi Barber (Coleoptera: Chrysomelidae), was compared to another three-component mixture of chemically related compounds. In the latter mixture, 1,2,4-trimethoxybenzene substituted veratrole (syn.: 1,2-dimethoxybenzene), $(E)$-cinnamic aldehyde substituted phenylacetaldehyde (differing in one carbon length with a double bond), while indole was the third, common constituent in both combinations. The results showed that both mixtures exhibited similar attractiveness for D. undecimpunctata adults, as well as for other Diabrotica species. 


\section{New attractant combinations}

In experiment 2, two new binary floral attractant combinations were found for C. a. aurata, of which 2-phenylethanol plus 4-methoxyphenethyl alcohol was superior to 2-phenylethanol plus isosafrol (Fig. 2). Four new binary floral attractant combinations of 2-phenylethanol with 1,2,4-trimethoxybenzene, methyl salicylate, 4-oxoisosporone and 4-methoxyphenethyl alcohol were identified for $P$. cuprea, the first and last being superior to the other two.

In South Africa, Donaldson et al. (1990) found that more than half of the 69 floral compounds tested showed significant attraction to cetoniin chafers, which suggests that they (including the species studied in the present research) may respond to a relatively large array of floral volatiles. This hypothesis is supported by the results of Experiment 2.

Similarities and differences in responses to floral compounds of C. a. aurata and P. cuprea

On the one hand, the present results show similarities in attraction to floral compounds of C. a. aurata and P. cuprea (Experiment 1). Furthermore, in Experiment 2, the combination of 2-phenylethanol and 4-methoxyphenethyl alcohol similarly attracted both chafer species, which also gave similar positive behavioural response in tendency to the combinations of 2-phenylethanol with methyl salicylate and 4-oxoisophorone, and lacked the behavioural response to 2-phenylethanol alone.

On the other hand, we found significant differences in the responses of the two cetoniin species, $P$. cuprea showing strong attraction to the combination of 2-phenylethanol with 1,2,4-trimethoxybenzene, whereas $C$. a. aurata did not (Fig. 2). The ratio of $P$. cuprea to $C$. $a$. aurata in traps baited with the above binary combination was greater as compared to the same ratio in traps containing 2-phenylethanol and 4-methoxyphenethyl alcohol as a lure which, however, caught the highest absolute numbers of both chafer species (Fig. 3). On the contrary, the combination of 2-phenylethanol with isosafrol elicited significant attraction only from $C$. a. aurata, but not from $P$. cuprea (Fig. 2). The P. cuprea ratio in this latter treatment was similar to that in the treatment with 2-phenylethanol and 4-methoxyphenethyl alcohol (Fig. 3).

Another floral compound, geraniol, elicited stronger attraction from P. cuprea than from C. a. aurata. Consequently, different combinations of geraniol (Vuts et al., 2010b) and 1,2,4-trimethoxybenzene (present study) could lead to a more selective bait for $P$. cuprea. There is also an opportunity to develop more selective floral-based lures for C. a. aurata by combining compounds eliciting a more specific response, such as phenylacetaldehyde (Imrei, 2003) and isosafrol (present study).

\section{Occurrence of the new attractant components in plants}

and their role in insect chemical communication

Both $C$. a. aurata and $P$. cuprea feed on the generative parts of a wide range of species mostly within the Rosaceae. Listing floral compounds produced by these plant families may help to understand the response to host plants from a chemical communication point of view (Table 1). 
Table 1

Occurrence of compounds, tested in Experiment 2, in plants, and their field activity in cetoniin chafers

\begin{tabular}{lll}
\hline Floral volatile & Plant family & Reference \\
\hline 1,2,4-trimethoxybenzene & Cucurbitaceae, Ericaceae, Hyacinthaceae, & Knudsen et al. (2006) \\
& Malvaceae, Oleaceae & \\
4-methoxyphenethyl & Annonaceae & Jürgens et al. (2000); \\
alcohol & Araceae & Kite and Hetterscheid (1997); \\
& Hyacinthaceae and Orchidaceae & Knudsen et al. (2006) \\
4-oxoisophorone & Apiaceae, Asteraceae, Dipsacaceae, Iridaceae, & Knudsen et al. (2006) \\
& Orchidaceae, Polemoniaceae, Scrophulariaceae, & \\
Theophrastaceae & \\
methyl salicylate & Asteraceae & Ronis et al. (2001) \\
& Arecaceae, Asteraceae, Brassicaceae, Caprifo- & Knudsen et al. (2006) \\
& liaceae, Fabaceae, Hyacinthaceae, Lauraceae, & \\
& Malvaceae, Moraceae, Orchidaceae, Rutaceae, & \\
& Solanaceae, Violaceae & \\
\hline
\end{tabular}

\section{3-Methyl eugenol, eugenol, isoeugenol}

All three eugenol-type floral compounds are widespread in many plant families, with largely overlapping occurrence (Knudsen et al., 2006). The significant positive response of C. a. aurata and P. cuprea to 3-methyl eugenol could be because this compound indicates the general presence of host plants, without any specificity to plant taxa.

\section{4-Methoxyphenethyl alcohol}

Similarly to the present results, Vuts et al. (2010c) showed a significant increase of $E$. hirta catches as a result of the addition of 4-methoxyphenethyl alcohol to the binary attractant combination of (E)-cinnamyl alcohol and (E)-anethol. Interestingly, 4-methoxyphenethyl alcohol was only described in a few plant families not represented by indigenous species within Europe (Table 1).

\section{Methyl salicylate}

Methyl salicylate is a widespread floral constituent present in several insect-pollinated plant families (Table 1). In the present study, methyl salicylate in combination with 2-phenylethanol elicited significant attraction from P. cuprea, but not from C. a. aurata (occasional catches only), despite being one of the most EAG-active compounds in (Vuts et al., 2010b), although with no field activity (Vuts et al., 2008). Similarly, methyl salicylate evoked large EAG responses in a related species, $O$. funesta, without significant field effect (Vuts et al., 2010c). Methyl salicylate is a widespread floral constituent present in several insect-pollinated plant families (Table 1).

On the other hand, females of the coffee berry borer, Hypothenemus hampei (Ferrari) (Coleoptera: Scolytidae) and its two parasitoids Prorops nasuta Waterstone and Phymastichus coffea (LaSalle) (Hymenoptera: Bethylidae), were attracted to methyl salicylate in olfactometer bioassays (Cruz-Lopez et al., 2016). Gencer et al. (2017) showed that bi- 
nary blends of methyl salicylate with benzaldehyde or with an unknown farnesene isomer were attractive for Hippodamia variegata Goeze (Coleoptera: Coccinellidae) adults. According to James (2003), Geocoris pallens Stal. (Hemiptera: Lygaeoidea) and hoverflies (Diptera: Syrphidae) were attracted to methyl salicylate in field experiments. James and Price (2004) showed that methyl salicylate captured significantly greater numbers of five species of the predatory insects Chrysopa nigricornis Burmeister (Neuroptera, Chrysopidae), Hemerobius sp. (Neuroptera, Hemerobiidae), Deraeocoris brevis Uhler (Hemiptera, Miridae), Stethorus punctum picipes Casey (Coleoptera, Coccinellidae) and Orius tristicolor White (Heteroptera, Anthocoridae), and species from the Syrphidae, Braconidae, Empididae and Sarcophagidae families.

\section{1,2,4-Trimethoxybenzene}

A new floral attractant discovered in the present study, enhancing catches of $P$. $c u$ prea but not $C$. a. aurata, which is produced by many plant families including several present in Europe (Table 1). 1,2,4-Trimethoxybenzene in combination with indole and (E)-cinnamaldehyde is a known attractant of several Luperini spp. (Chrysomelidae), including the western striped cucumber beetle, Acalymma trivittaum F., the spotted cucumber beetle, D. undecimpunctata howardi Barber and the western corn rootworm, D. virgifera virgifera LeConte (Lampman and Metcalf, 1987; Hoffmann et al., 1996; Andrews et al., 2007).

\section{Isosafrol}

It occurs in minute quantities in herbal oils (Table 1). In the present study, in combination with 2-phenylethanol it evoked significant attraction of $C$. a. aurata, but not P. cuprea. Huang et al. (1999) showed a strong feeding deterrent effect of isosafrol on Sitophilus zeamais Motschulsky (Coleoptera: Curculionidae). Donaldson et al. (1990) found isosafrol to be one of the most attractive compounds tested for Cetoniinae species, such as Oxythyrea spp., Clinteroides permutans (Burmeister) and Plaesiorrhina reeurva plana (Wiedemann).

\section{4-Oxoisophorone}

The combination of 2-phenylethanol and 4-oxoisophorone had a significant attractant effect on $P$. cuprea only. 4-Oxoisophorone, despite being less common in plants, occurs in a number of plant families native to Europe (Table 1). The blend of 4-oxoisophorone and phenylacetaldehyde was found to be attractive to the orange mint moth, Pyrausta orphisalis Walker, and to the false celery leaftier moth, Udea profundalis Packard (Lepidoptera: Crambidae) (Landolt et al., 2014). 


\section{Acknowledgements}

This work was supported in part by

- funding from INSECTLIFE Innovative Real-time Monitoring and Pest control for Insects (LIFE13 ENV/HU/001092) to Miklós Tóth,

- János Bolyai Research Scholarship of the Hungarian Academy of Sciences for József Fail, and

- József Vuts in the frames of Rothamsted Research receive grant aided support from the Biotechnology and Biological Sciences Research Council of the United Kingdom.

\section{Literature}

Andrews, E. S., Theis, N. and Adler, L. S. (2007): Pollinator and herbivore attraction to Cucurbita floral volatiles. J. Chem. Ecol. 33, 1682-1691.

Chen, R. and Li, Y. (2011): A novel plant volatile attractant scheme to protect corn in China from the white-spotted flower chafer (Coleoptera: Scarabaeidae: Cetoniinae). J. Pest Science 84, 327-335.

Cruz-Lopez, L., Diaz-Diaz, B. and Rojas, J. C. (2016): Coffee volatiles induced after mechanical injury and beetle herbivory attract the coffee berry borer and two of its parasitoids. Arthropod-Plant Interactions 10, 151-159.

Donaldson, J. M. I., McGovern, T. P. and Ladd, J. R. (1990): Floral attractants for Cetoniinae and Rutelinae (Coleoptera: Scarabaeidae). J. Econ. Entomol. 83, 1298-1305.

Gencer, N. S., Kumral, N. A., Seidi, M. and Pehlevan, B. (2017): Attraction responses of ladybird beetle Hippodamia variegata (Goeze, 1777) (Coleoptera: Coccinellidae) to single and binary mixture of synthetic herbivore-induced plant volatiles in laboratory tests. Turkish J. Entomology 41, 17-26.

Hoffmann, M. P., Kirkwyland, J. J., Smith, R. F. and Long, R. F. (1996): Field tests with kairomone-baited traps for cucumber beetles and corn rootworms in cucurbits. Department of Entomology, Cornell University, Ithaca. 25, 1173-1181.

Hommonay, F. and Hommonayné-Csehi, É. (1990): Cserebogarak - Melolonthidae. In: T. Jermy and K. Balázs (eds): A növényvédelmi állattan kézikönyve (Handbook of Plant Protection Zoology) III/A. 156-215.

Huang, Y., Ho, S. H. and Kini, R. M. (1999): Bioactivities of safrole and isosafrole on Sitophilus zeamais (Coleoptera: Curculionidae) and Tribolium castaneum (Coleoptera: Tenebrionidae). J. Econ. Entomol. $92,676-683$.

Hurpin, B. (1962): Super-Famille des Scarabaeoidea. In: A. S. Balachowsky (ed.): Entomologie Appliquée a 1'Agriculture. Masson et Cie Éditeurs, Paris, 24-204.

Imrei, Z. (2003): Chemical communication of pest beetles. PhD Thesis, Corvinus Universtiy, Budapest.

Imrei, Z. and Tóth, M. (2002): European common cockchafer (Melolontha melolontha L.): Preliminary results of attraction to green leaf odours. Acta Zoologica Academiae Scientiarum Hungaricae 48, 151-155.

James, D. G. (2003): Synthetic herbivore-induced plant volatiles as field attractants for beneficial insects. Environ. Entomol. 32, 977-982.

James, D. G. and Price, T. S. (2004): Field-testing of methyl salicylate for recruitment and retention of beneficial insects in grapes and hops. J. Chem. Ecol. 30, 1613-1628.

Jürgens, A., Webber, A. and Gottsberger, G. (2000): Floral scent compounds of Amazonian Annonaceae species pollinated by small beetles and thrips. Phytochemistry 55, 551-558.

Kite, G. C. and Hetterscheid, W. L. A. (1997): Inflorescence odours of Amorphophallus and Pseudodracontium (Araceae). Phytochemistry 46, 71-75.

Knudsen, J. T., Eriksson, R., Gershenzon, J. and Stahl, B. (2006): Diversity and distribution of floral scent. The Botanical Review 72, 1-120.

Lampman, R. L. and Metcalf, R. L. (1987): Multicomponent kairomonal lures for southern and western corn rootworms (Coleoptera: Chrysomelidae: Diabrotica spp.). J. Econ. Entomol. 80, 1137-1142.

Landolt, P., Cha, D. and Davis, T. S. (2014): Attraction of the orange mint moth and false celery leaftier moth (Lepidoptera: Crambidae) to floral chemical lures. J. Econ. Entomol. 107, 654-660. 
Lee, J. E., Jo, D. E., Lee, A. J., Park, H. K., Youn, K., Yun, E. Y., Hwang, J. S., Jun, M. and Kang, B. H. (2014): Hepatoprotective and antineoplastic properties of Protaetia brevitarsis larvae. Entomol. Res. 44, 244-253.

Ronis, M., Rowlands, J., Hakkak, R. and Badger, T. (2001): Inducibility of hepatic CYP1A enzymes by 3-methylcholanthrene and isosafrole differs in male rats fed diets containing casein, soy protein isolate or whey from conception to adulthood. The J. Nutrition 131, 1180-1188.

Schmera, D., Tóth, M., Subchev, M., Sredkov, I., Szarukan, I., Jermy, T. and Szentesi, A. (2004): Importance of visual and chemical cues in the development of an attractant trap for Epicometis (Tropinota) hirta Poda (Coleoptera: Scarabaeidae). Crop Prot. 23, 939-944.

Tóth, M., Klein, K. G. and Imrei, Z. (2003): Field screening for attractants of scarab (Coleoptera: Scarabaeidae) pests in Hungary related information. Acta Phytopath. et Entomol. Hung. 38, 3-4.

Tóth, M., Schmera, D. and Imrei, Z. (2004): Optimization of a chemical attractant for Epicometis (Tropinota) hirta Poda. Z. Naturforsch. C 59, 288-292.

Tóth, M., Imrei, Z., Szarukán, I., Voigt, E., Schmera, D., Vuts, J., Harmincz, K. and Subchev, M. (2005): Chemical communication of fruit- and flower-damaging scarabs: results of one decade's research efforts. Növényvédelem 41, 581-588. (In Hungarian).

Voigt, E., Tóth, M., Imrei, Z., Vuts, J., Szőllős, L. and Szarukán, I. (2005): A zöld cserebogár és az aranyos rózsabogár növekvő kártétele és a környezetkímélő védekezés lehetőségei. [Damages by Anomala vitis and Cetonia aurata (Coleoptera: Scarabaeiade) and possibilities for environmentally harmless control]. Agrofórum 16, 63-64. (In Hungarian).

Vuts, J., Imrei, Z. and Tóth, M. (2008): Development of an attractant-baited trap for Oxythyrea funesta Poda (Coleoptera: Scarabaeidae, Cetoniinae). Z. Naturforsch. C 63, 761-768.

Vuts, J., Baric, B., Razov, J., Toshova, T. B., Subchev, M., Sredkov, I., Tabilio, R., Di Franco, F. and Tóth, M. (2010a): Performance and selectivity of floral attractant-baited traps targeted for cetoniin scarabs (Coleoptera: Scarabaeidae) in Central and Southern Europe. Crop Prot. 29, 1177-1183.

Vuts, J., Imrei, Z. and Tóth, M. (2010b): New co-attractants synergizing attraction of Cetonia aurata aurata and Potosia cuprea to the known floral attractant. J. Appl. Entomol. 134, 9-15.

Vuts, J., Szarukán, I., Subchev, M., Toshova, T. and Tóth, M. (2010c): Improving the floral attractant to lure Epicometis hirta Poda (Coleoptera: Scarabaeidae, Cetoniinae). J. Pest Science 83, 15-20.

Vuts, J., Kaydan, M. B., Yarimbatman, A. and Tóth, M. (2012): Field catches of Oxythyrea cinctella using visual and olfactory cues. Physiol. Entomol. 37, 92-96. 